\title{
Self-Organization Phenomena in Embryonic Stem Cell-Derived Embryoid Bodies: Axis Formation and Breaking of Symmetry during Cardiomyogenesis
}

\author{
Christiane Fuchs $^{\mathrm{a}}$ Matthias Scheinast ${ }^{\mathrm{a}}$ Waltraud Pasteiner ${ }^{\mathrm{a}}$ Sabine Lagger ${ }^{\mathrm{b}}$ \\ Manuela Hofner $^{\mathrm{a}} \quad$ Alexandra Hoellrigl $^{\mathrm{a}} \quad$ Martina Schultheis ${ }^{\mathrm{a}}$ Georg Weitzer $^{\mathrm{a}}$ \\ ${ }^{a}$ Max F. Perutz Laboratories, Department of Medical Biochemistry, Division of Molecular Biology and \\ ${ }^{\mathrm{b}}$ Division of Molecular Genetics, Medical University of Vienna, Vienna, Austria
}

\section{Key Words}

Embryonic stem cells - Stem cell differentiation - Embryoid bodies $\cdot$ Morphogenesis $\cdot$ Cardiomyogenesis $\cdot$ Mouse

\begin{abstract}
Aggregation of embryonic stem cells gives rise to embryoid bodies (EBs) which undergo developmental processes reminiscent of early eutherian embryonic development. Development of the three germ layers suggests that gastrulation takes place. In vivo, gastrulation is a highly ordered process but in EBs only few data support the hypothesis that selforganization of differentiating cells leads to morphology, reminiscent of the early gastrula. Here we demonstrate that a timely implantation-like process is a prerequisite for the breaking of the radial symmetry of suspended EBs. Attached to a surface, EBs develop a bilateral symmetry and presumptive mesodermal cells emerge between the center of the EBs and a horseshoe-shaped ridge of cells. The development of an epithelial sheet of cells on one side of the EBs allows us to define an 'anterior' and a 'posterior' end of the EBs. In the mesodermal area, first cardiomyocytes (CMCs) develop mainly next to this epithelial sheet of cells. Development of
\end{abstract}

twice as many CMCs at the 'left' side of the EBs breaks the bilateral symmetry and suggests that cardiomyogenesis reflects a local or temporal asymmetry in EBs. The asymmetric appearance of CMCs but not the development of mesoderm can be disturbed by ectopic expression of the muscle-specific protein Desmin. Later, the bilateral morphology becomes blurred by an apparently chaotic differentiation of many cell types. The absence of comparable structures in aggregates of cardiovascular progenitor cells isolated from the heart demonstrates that the self-organization of cells during a gastrulation-like process is a unique feature of embryonic stem cells.

Copyright $\odot 2011$ S. Karger AG, Basel

\section{Abbreviations used in this paper}

AP alkaline phosphatase

CMCs cardiomyocytes

EBs embryoid bodies

ECM extracellular matrix

ESCs embryonic stem cells

\section{KARGER}

Fax +4161306 1234

E-Mail karger@karger.ch

www.karger.com
C) 2011 S. Karger AG, Basel

1422-6405/12/1955-0377\$38.00/0

Accessible online at:

www.karger.com/cto
Ao. Univ. Prof. Dr. Georg Weitzer

Max F. Perutz Laboratories, Department of Medical Biochemistry

Medical University of Vienna, Dr. Bohrgasse 9/3

AT-1030 Vienna (Austria)

Tel.+43 14277 61650, E-Mail georg.weitzer@univie.ac.at 


\section{Introduction}

Embryonic stem cell (ESC)-derived embryoid bodies (EBs) provide the environment for lineage commitment to the ectodermal, mesodermal and endodermal fate [Wobus et al., 1984; Desbaillets et al., 2000; Dvash et al., 2006; Yamanaka et al., 2008]. In suspension, aggregated ESCs form an outer layer of primitive endoderm [Murray and Edgar, 2001; Rula et al., 2007] resembling the hypoblast of the implanting blastocyst. The inner cells adopt an ectodermal fate, forming a columnar epithelium [Ikeda et al., 1999; Komura et al., 2008], which resembles the epiblast and later the early egg cylinder stage at day 6.5 (E6.5) of murine embryogenesis. Maintenance of EBs in suspension culture leads to the formation of many somatic cell types of ectodermal, mesodermal and endodermal origin. Mesoderm has been shown to emerge in a Wnt-signaling-dependent, localized and asymmetric manner in EBs kept in suspension [ten Berge et al., 2008].

Alternatively, EBs may be transferred to tissue culture plates coated with components of the extracellular matrix (ECM), where they attach via the primitive endoderm, which thereupon migrate radially from the dense center of the EBs. Primitive endoderm differentiates to the extraembryonic visceral and parietal endoderm which in vivo compose the two yolk sacs of the mammalian embryo. The primitive ectoderm undergoes locally an epithelial-mesenchymal transition which results in the development and ingression of mesoderm [Behr et al., 2005; Denker et al., 2007; Maranca-Hüwel and Denker, 2010]. If EBs have been formed from 600 to 800 ESCs, the dense center of the attached EBs enlarges and occasionally a horseshoe-shaped ridge of cells forms, which surrounds the central core of the EBs [Weitzer, 2006]. Cells in the area encircled by the horseshoe-shaped ridge of cells become committed to Brachyury-expressing primitive mesoderm [Bader et al., 2001]. These mesodermal precursors give rise to hematopoietic cells and spontaneously and rhythmically contracting cardiomyocytes (CMCs). First, CMCs start to contract at the same time as the heart tube forms at E7.5 to E8.0 from the splanchnic or lateral plate mesoderm located underneath the ectodermal head fold of the embryo. Nonetheless, lineage development in EBs which commences during gastrulation in vivo has until now been mainly considered to be chaotic.

Patterning of mesoderm is orchestrated by the interplay of many growth factors with morphogenetic activities. The influence of Tgf $\beta$ and Wnt signaling is well studied [ten Berge et al., 2008]. An Activin A/Nodal gradient influences the expression of the transcription factors
Brachyury, Goosecoid, and Mix [Dvash et al., 2007; Nakaya et al., 2008]. However, Nodal is also reported to inhibit mesoderm development by supporting the self-renewal of ESCs [Vallier et al., 2004, 2009]. Both low and high levels of Nodal activate Brachyury, but with different developmental outcomes. Posterior mesoderm forms at low levels of Nodal or when Wnt3a is present. Nodal maintains expression of Brachyury, inactivates Mix, and consequently Goosecoid is repressed. In contrast, anterior mesoderm forms in the presence of high Nodal levels or when Wnt signaling is inhibited. Nodal induces the expression of Mix which in turn inactivates Brachyury by activating Goosecoid. Consequently, posterior mesoderm forms at the expense of anterior mesoderm and definitive endoderm [Swiers et al., 2010], and development of the neuroectodermal lineage can proceed.

Cardiomyogenesis is induced and regulated by a set of transcription factors and extracellular signals committing primitive mesodermal cells to the cardiogenic lineage. Sequential and parallel expression of Brachyury, MesP1, Gata4, Nkx2.5, and Is11 in mesodermal progenitor cells leads to the commitment of these cells to the cardiogenic lineage, and to the expression of transcription factors instructing cells to differentiate to the myocardial, smooth-muscle and endothelial fate [Laugwitz et al., 2008]. Shortly after the expression of Brachyury, cells committed to the myogenic lineage begin to express Desmin and differentiate first to CMCs, and later on to smooth muscle cells, skeletal muscle myoblasts and myotubes, both in vivo [Kuisk et al., 1996] and in EBs [Weitzer et al., 1995]. Desmin promotes cardiomyogenesis in vitro [Hofner et al., 2007; Höllrigl et al., 2007], but is dispensable during embryogenesis due to redundant functions of other type III intermediate filament proteins [Li et al., 1996; Milner et al., 1996].

From the first description of ESC-derived EBs [Wobus et al., 1984], it became more and more evident that EBs mimic the triploblastic development of eutherian embryos. Despite the fact that ectodermal, endodermal and mesodermal somatic cells could be identified in differentiating EBs, morphological processes resembling embryonic gastrulation could so far only be identified in rhesus monkey EBs when attached to a surface [Behr et al., 2005; Denker et al., 2007; Maranca-Huwel and Denker, 2010] and in suspension cultures of mouse [ten Berge et al., 2008] and human EBs [Kopper et al., 2010]. Most other data hinted at a rather chaotic development of the three germ layers in EBs [Pekkanen-Mattila et al., 2010]. In contrast, pregastrulation development of the blastocyst leading to the formation of the epiblast and the endoblast, 
including its derivatives visceral and parietal endoderm, is very well recapitulated in EBs [Ikeda et al., 1999; Bader et al., 2001; Murray and Edgar, 2001; Stary et al., 2005]. Thus, here we try to demonstrate that attachment of EBs to an ECM-mimicking implantation provides the foundation for a reproducible morphological development reminiscent of early mammalian gastrulation. Indeed, EB development follows a morphological program inherent and restricted to ESC-derived EBs. Under a rigorous regime, including constant numbers of ESCs and exact timing of the attachment of EBs, self-organization of cells in EBs establishes a bilateral symmetry which is temporally broken when cardiomyogenesis commences. Finally, these developmental processes during early cardiomyogenesis can be disturbed by interfering with Nodal signaling or by the ectopic expression of Desmin.

\section{Materials and Methods}

Maintenance and Differentiation of ESCs

AB2.2 [Soriano et al., 1991], W4 [Lauss et al., 2005], 663 wildtypeESCsand 664 $\left(\mathrm{hdacl}^{-/-}\right)$[Lagger et al., 2002], DC6 $\left(\mathrm{des}^{+/+} \mathrm{des}^{\mathrm{ect}}\right)$ [Hofner et al., 2007], 6.24.14.24 (des $\left.{ }^{-/}\right)$[Weitzer et al., 1995], DIC2 $\left(\right.$ lif $^{--}$) [Dani et al., 1998] and DIA-RKO (lifr-/-) [Aubert et al., 1999] ESCs were maintained in DMEM containing $2 \mathrm{mmol} / \mathrm{l}$ glutamine, $50 \mathrm{U} / \mathrm{ml}$ penicillin, $50 \mu \mathrm{g} / \mathrm{ml}$ streptomycin, $0.1 \mathrm{mmol} / \mathrm{l}$ $\beta$-mercaptoethanol, and 15\% (v/v) fetal bovine serum (HyClone SH30070.30, lot ASK30724; M15Hy) on mitomycin C-inactivated feeder cells prepared from SNL76/7 fibroblasts [McMahon and Bradley, 1990] as previously described [Lauss et al., 2005].

To generate EBs, ESCs were grown to confluence on feeder cells and split 1:2 on the day before aggregation. The next day, ESCs were dissociated by trypsinization and suspended in M15Si. M15Si had an identical composition to M15Hy with the exception of using a different fetal bovine serum (Sigma F7524). Feeder cells were removed by adsorption on gelatine-coated tissue culture plates at $37^{\circ} \mathrm{C}$ for $60 \mathrm{~min}$. ESCs remaining in the supernatant were diluted to $4 \times 10^{4}$ cells $/ \mathrm{ml} \mathrm{M15Si}$ and $90 \pm 1020-\mu l$ drops were placed on the lids of bacterial-grade $10-\mathrm{cm}$ plates. Drops were incubated over a layer of sterile water at $37^{\circ} \mathrm{C}$ for 4.5 days to compensate the increased vapor pressure of the drops. Aggregates were then washed from the lid into gelatine-coated tissue culture plates with $6 \mathrm{ml}$ of M15Si, were evenly distributed, and fed every 3 days exactly as described [Bader et al., 2000a]. SB431542 SigmaAldrich (S4317) was dissolved in DMSO at a concentration of $1 \mathrm{mmol} / \mathrm{l}$. Recombinant Nodal was from R\&D Systems (1315ND) and used at a concentration of $58 \mathrm{nmol} / \mathrm{l}$. As a control, DMSO alone was added to M15Si. All cell lines used in this study maintained a stable phenotype over more than 50 passages.

Cardiovascular progenitor cells were isolated by a modified $3 \mathrm{~T} 3$ protocol from murine hearts, subcloned and maintained as monoclonal cell lines with constant chromosome numbers and a stable phenotype for up to 126 passages. Maintenance and differentiation were performed exactly as for ESCs, with the exception that a concentration of $4.5 \times 10^{4}$ cells $/ \mathrm{ml}$ was used for aggrega- tion in hanging-drop cultures and aggregates were transferred at day 4.7 to tissue culture dishes. Higher cell numbers and prolonged culture in the drops compensated the lower readiness of these cells to aggregate. These cells exclusively differentiate to cell types of mesodermal origin.

\section{Confocal Immunofluorescence Microscopy}

EBs on coverslips were washed once in PBS and fixed in $96 \%$ ethanol at $-20^{\circ} \mathrm{C}$ for $20 \mathrm{~min}$, then dried and blocked with $1 \%$ bovine serum albumin in PBS for 10 min. After washing EBs in PBS for $10 \mathrm{~min}$, they were stained with antibodies against cardiac Troponin T (Thermo Scientific \#MS-295, 1:200), Connexin 43 (Sigma C6219, 1:400), $\beta$-catenin (Transduction Labs C19220, 1:200), Desmin (Sigma-Aldrich D8281, 1: 200), Ki67 (Novocastra Laboratories, NCL Ki67p, 1:1,000), Snail 1 (Abcam, ab17732, 1:100) and E-cadherin (BD Transduction Laboratories, \#610181, 1:100) for 60 min, and consecutively with FITC-, Alexa Fluor 488-, and TRITCconjugated secondary antibodies (Dianova, 711-095-152, 1:200; 711-095-151, 1:200; 711-075-152, 1:200, Invitrogen A11008, Sigma F4018, 1:200, T5268, 1:80) for $60 \mathrm{~min}$. Secondary antibodies were tested alone to exclude background staining. Nuclei were stained with DAPI or propidium iodide, and photomicrographs were taken on a Zeiss LSM 510 confocal microscope.

Alternatively, EBs maintained in suspension culture were fixed in $4 \%$ para-formaldehyde overnight at $4^{\circ} \mathrm{C}$, then washed twice in cold PBS for $30 \mathrm{~min}$ at $4^{\circ} \mathrm{C}$. Until embedding, EBs were stored in 70\% ethanol. Due to the small size of EBs, 5-10 EBs were collected and sealed in low-melting agar in order to facilitate dehydration and sectioning. Consequent dehydration of EBs in agar was performed according to standard histological methods using the Excelsior tissue processor. After paraffin embedding, EBs were sectioned into $5-\mu \mathrm{m}$ tissue sections. For staining EB paraffin sections, the TSA Kit (Perkin Elmer) was used. In short, sections were heated to $60^{\circ} \mathrm{C}$ for $1 \mathrm{~h}$ and rehydrated. Antigens were retrieved by boiling the sections in citric acid for $20 \mathrm{~min}$. After three washing steps in TNT buffer $(0.1 \mathrm{~mol} / \mathrm{l}$ Tris/ $\mathrm{HCl} \mathrm{pH} \mathrm{7.5,0.15} \mathrm{mol} / \mathrm{l}$ $\mathrm{NaCl}, 0.05 \%$ Tween 20 ), endogenous peroxidase was blocked with $3 \% \mathrm{H}_{2} \mathrm{O}_{2}$ for $60 \mathrm{~min}$. In the next step, unspecific antibody binding was blocked using blocking reagent from Perkin Elmer and sections were incubated with primary antibodies in a humid chamber overnight at $4^{\circ} \mathrm{C}$. On the following day, sections were again washed in TNT buffer and incubated with the horseradish peroxidase-conjugated secondary antibodies corresponding to the species of the primary antibody for $30 \mathrm{~min}$ at room temperature. After three washes in TNT buffer, signals were amplified using TSA fluorescent dyes (1:100 in amplification diluents) for $10 \mathrm{~min}$ in the dark. Finally, remaining horseradish peroxidase activity was deactivated by incubation of sections with $1 \% \mathrm{H}_{2} \mathrm{O}_{2}$ for 15 min. Sections were mounted with Prolong Gold containing DAPI (Invitrogen) and analyzed on either an LSM Meta Confocal Microscope or a Fluorescence Microscope, both from Zeiss.

In vivo Staining of Cells in EBs and Light Microscopy

The activity of alkaline phosphatase (AP) in cells was detected after washing EBs each once with PBS and AP buffer solution (100 $\mathrm{mmol} / \mathrm{l}$ Tris- $\mathrm{HCl} \mathrm{pH}$ 9.5, $100 \mathrm{mmol} / \mathrm{l} \mathrm{NaCl}, 50 \mathrm{mmol} / \mathrm{l} \mathrm{MgCl}_{2}$ ) and the addition of a freshly prepared solution of $0.34 \mathrm{mg} / \mathrm{ml} \mathrm{NBT}$ and $0.18 \mathrm{mg} / \mathrm{ml} \mathrm{BCIP}$ in AP buffer at room temperature for $5 \mathrm{~min}$.

To detect heavily glycosylated surfaces of primitive, visceral and parietal endoderm cells [Stary et al., 2005], a 0.1\% (w/v) tolu- 


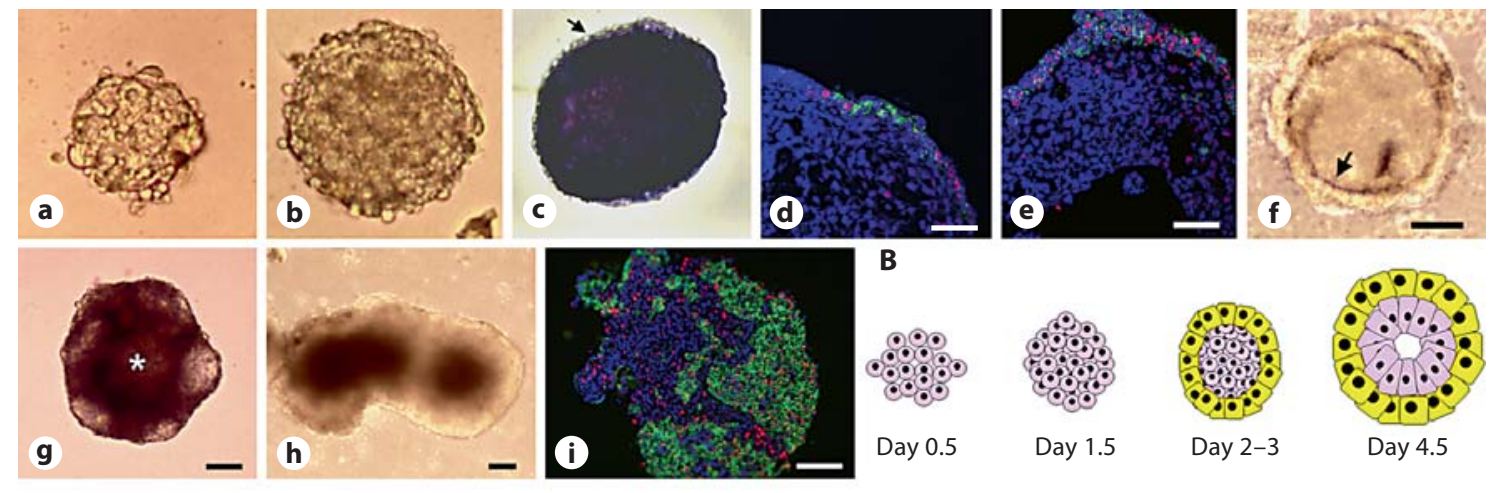

C
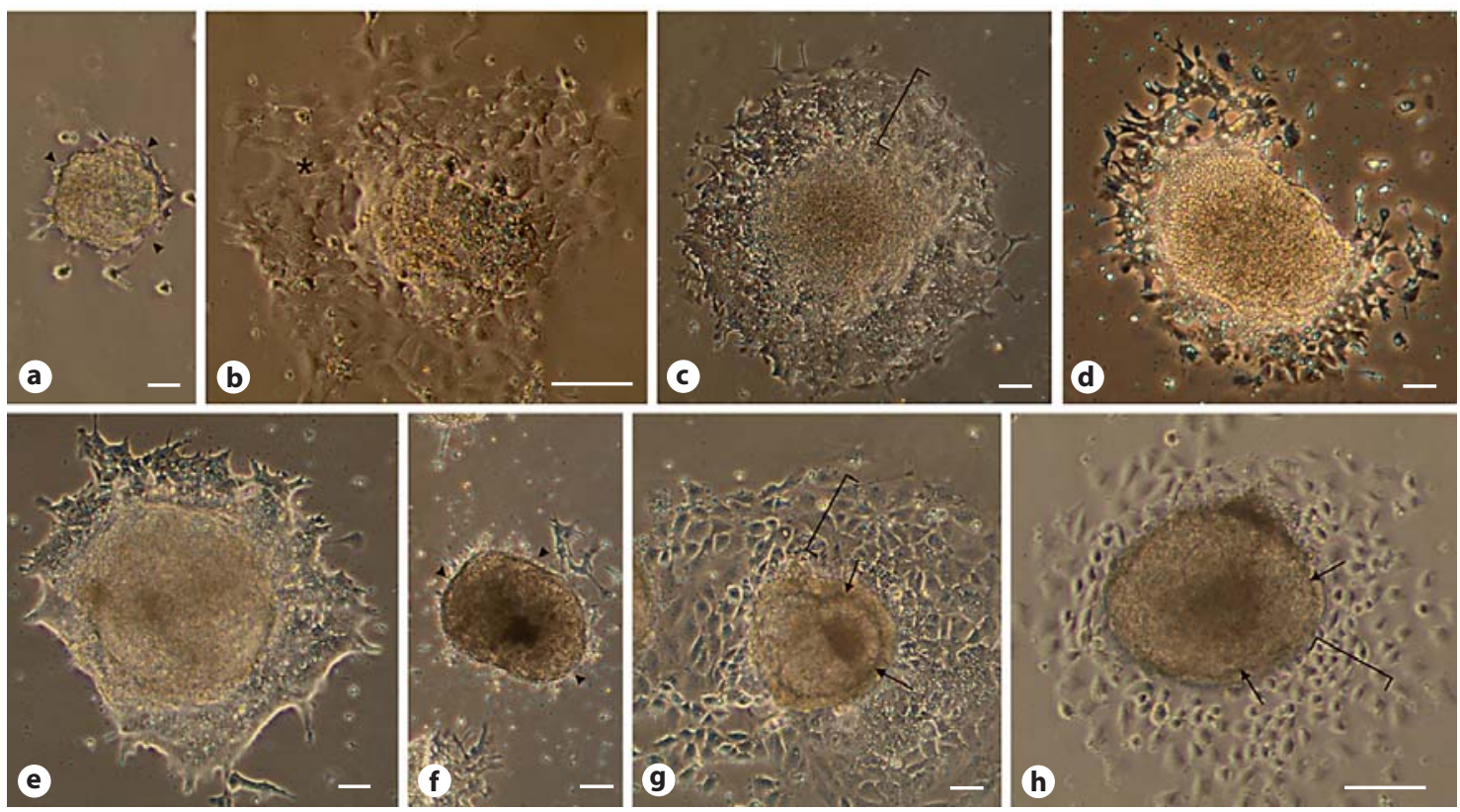

Fig. 1. Radial symmetry of solitary EBs in hanging-drop cultures. A 800 ESCs were aggregated in $20-\mu$ l drops for 4.5 days and then transferred to the suspension culture. ESCs aggregate within 1.5 days (a) and the compacted EB grows in size from day 2 to day 4.5 (b). At day 4.5 most cells are still AP-positive (c) with the exception of the outer layer of primitive endoderm (arrow). Primitive endoderm increasingly expresses Snail (red) and E-cadherin (green) (d, e). At the same time a Reichert's membrane-like borderline (arrow) between the inner cells and the outer layer of primitive endoderm forms (f). If EBs were maintained in suspension culture the AP-positive cells became less from day 5 onwards (g) and a central cavity $\left(^{*}\right)$ formed, EBs developed mostly an irregular shape (h) and cells were distributed in an apparently chaotic manner as made evident by E-cadherin (green) and Snail (red) staining at day 10 (i). DNA was stained with DAPI (blue). a-i Bars: $100 \mu \mathrm{m}$. B Cartoon demonstrating the early development of cell types in EBs. Pink: ESCs and primitive ectodermal cells; yellow: primitive endoderm. C If EBs were transferred from the hanging drops to tissue culture plates at day 2 (a) or 3 (b) they did not further differentiate but remained as ESC-like colonies (arrowheads indicate area where primitive endoderm usually starts to grow and give rise to parietal endoderm; * = ESC-like cells). When plated on day 4.5 , the primitive endoderm readily attached to the gelatine-coated tissue culture plate and differentiation proceeded with a radial symmetry (bracket in c). If plated on day 5.5, many EBs developed an irregular shape (d); however, differentiation proceeded normally in most cases 1-2 days later (e). If EBs were transferred to the tissue culture plate on day 6.5 or later, their development was either totally blocked (f, arrowheads as in a) or only extraembryonic endoderm formed (brackets in $\mathbf{g}$ and $\mathbf{h}$ ), while the inner cells remained entrapped within the Reichert's membrane-like structure (arrows in $\mathbf{g}$ and $\mathbf{h}$ ). Phase contrast images taken 1 day $(\mathbf{a}-\mathbf{d}, \mathbf{f}, \mathbf{h})$ and 2 days $(\mathbf{e}, \mathbf{g})$ after the attachment of EBs. Bars: $100 \mu \mathrm{m}$. 
idine blue O (CAS\#92-31-9) solution in PBS was added to culture dishes after the medium was removed and attached EBs were washed once with PBS. After $10 \mathrm{~min}$ at room temperature plates were washed once with PBS.

Hemoglobin in hematopoietic cells was detected by mixing the culture medium $1: 1$ with a freshly prepared solution of $0.2 \%$ benzidine (w/v), $0.3 \% \mathrm{H}_{2} \mathrm{O}_{2}(\mathrm{v} / \mathrm{v})$, and $3 \%$ acetic acid at room temperature for $5 \mathrm{~min}$.

Dead cells were identified by the addition of a propidium iodide stock solution $(10 \mathrm{mg} / \mathrm{ml}$ in water $)$ to the medium at a final concentration of $5 \mu \mathrm{g} / \mathrm{ml}$.

Pictures were taken on an Olympus CK2 microscope under bright-field, phase-contrast, or dark-field illumination and prepared for publication by Adobe Photoshop CS2. Where indicated, pictures were composed from several microphotographic images or false coloring was overlaid to indicate areas with rhythmically contracting CMCs.

\section{Semiquantitative RT-PCR}

Total RNA was isolated from AB2.2 ESC-derived EBs on days 0 (ESCs), 4, 6, 9 and 12 with the Qiagen RNeasy kit. cDNA was synthesized with RevertAid M-MuLV Reverse Transcriptase (Fermentas, \#EP0441). Semiquantitative RT-PCR was performed with Taq polymerase (Fermentas \#EP0402) using the following primer pairs: AFP forward: 5'-GCTCACACCAAAGCGTCAAC3', AFP reverse: 5'-CCTGTGAACTCTGGTATCAG-3'; Brachyury forward: 5'-ATCAAGGAAGGCTTTAGCAAATGGG-3', Brachyury reverse: 5'-GAACCTCGGATTCACATCGTGAGA3'; Desmin forward: 5'-TGATGAGGCAGATGAGGGAG-3', Desmin reverse: 5'-TGAGAGCAGAGAAGGTCTGG-3'; GAPDH forward: 5'-CGTCTTCACCACCATGGAGA-3', GAPDH reverse: 5'-CGGCCATCACGCCACAGTTT-3'; Goosecoid forward: 5'-GCACCATCTTCACCGATGAG-3', Goosecoid reverse: 5'-AGGAGGATCGCTTCTGTCGT-3'. The number of cycles for each pair of primers was carefully optimized so that none of the obtained signals was saturated and equalized to GAPDH expression.

\section{Statistical Analysis}

Data are presented as the arithmetic mean \pm standard deviation. Statistical significance was evaluated using the one-sample Student $\mathrm{t}$ test and values of $\mathrm{p}<0.05$ were considered to indicate statistical significance.

\section{Results}

\section{Self-Organization in Early EBs Alludes to the Bilaterian Body Plan}

Here we describe that EBs undergo axis formation when they are first maintained individually in hangingdrop cultures and then transferred to tissue culture plates at a density of $1 \mathrm{~EB} / \mathrm{cm}^{2}$ at day 4.5 of their development. In hanging drops, nearly all EBs develop in a radial symmetrical manner for the first 4.5 days (fig. 1A, B). Since EBs never develop uniformly in $100 \%$ of a population, quantitative data for the images shown in figures 1-6 are
Table 1. Quantitative morphological data supporting the significance of images shown in figures 1-6

\begin{tabular}{lcrrc}
\hline Figure & $\begin{array}{l}\text { Frequency of occurrence } \\
\text { (mean value) of EBs }\end{array}$ & $\begin{array}{l}\text { EBs } \\
\mathrm{n}\end{array}$ & $\begin{array}{l}\text { Experiments } \\
\mathrm{n}\end{array}$ & $\begin{array}{l}\text { Error } \\
\text { SD }\end{array}$ \\
\hline $1 \mathrm{~A}, \mathrm{a}, \mathrm{b}$ & 99.6 & 800 & 10 & 0.8 \\
$1 \mathrm{~A}, \mathrm{c}$ & 100 & 170 & 2 & 0 \\
$1 \mathrm{~A}, \mathrm{~h}$ & 82.3 & 170 & 4 & 3.3 \\
$1 \mathrm{C}, \mathrm{d}$ & 82 & 300 & 10 & 12 \\
$2 \mathrm{~A}-\mathrm{G}$ & 99.6 & 800 & 10 & 0.8 \\
$2 \mathrm{H}-\mathrm{J}, 6 \mathrm{D}$ & 74 & 79 & 2 & 20.2 \\
$2 \mathrm{~K}, \mathrm{~L}$ & 47.8 & 54 & 9 & 31.1 \\
$2 \mathrm{M}-\mathrm{S}, 6 \mathrm{D}$ & 50.4 & 944 & 7 & 7.5 \\
$2 \mathrm{X}, \mathrm{Y}$ & 100 & 800 & 10 & 0 \\
$3 \mathrm{~A}, \mathrm{E}$ & 100 & 37 & 1 & - \\
$3 \mathrm{~B}, \mathrm{C}$ & 32 & 25 & 1 & - \\
$3 \mathrm{~F}$ & 100 & 800 & 10 & 0.0 \\
$4 \mathrm{~A}-\mathrm{C}^{2}$ & 89 & 624 & 8 & 11.0 \\
$4 \mathrm{G}^{2}$ & 81 & 148 & 8 & 19 \\
$5 \mathrm{~A}-\mathrm{C}$ & 100 & 14 & 4 & 0 \\
$6 \mathrm{~B}^{3}$ & 99 & 446 & 10 & 1.1 \\
$6 \mathrm{C}$ & 89 & 706 & 4 & 2.1 \\
$6 \mathrm{E}^{4}$ & 100 & 880 & 10 & 0 \\
\hline
\end{tabular}

Figures not included in this table have not been evaluated quantitatively.

${ }^{1}$ Values are most likely too low because the structures are often hidden by other cells. ${ }^{2}$ Data apply to EBs with beating cardiomyocytes. ${ }^{3}$ Data apply to des ${ }^{e c t}$ EBs only, for $\mathrm{des}^{+/+}$data see figure 2G. ${ }^{4}$ Data apply to cardiac bodies made from murine cardiovascular progenitor cells.

provided in table 1. During this time ESCs aggregate, compact (fig. $1 \mathrm{~A}, \mathrm{a}, \mathrm{b}$ ), give rise to an AP-expressing inner epiblast-like cell mass (fig. 1A, c) and an outer layer of primitive endodermal cells [Bader et al., 2001], increasingly expressing Snail and E-cadherin (fig. 1A, d, e). These two compartments were separated by a Reichert's membrane-like ECM [Henry and Campbell, 1998; Murray and Edgar, 2001] (fig. 1A, f).

If further maintained in suspension mass culture, many EBs form a cavity and the number of AP-expressing cells declines (fig. 1A, g). After 3-5 days, EBs develop an asymmetrical shape (fig. $1 \mathrm{~A}, \mathrm{~h}$ ) with a rather chaotic distribution of cells at day 10 (fig. 1A, i). The time of transfer of EBs from hanging-drop cultures to plates coated with gelatine is crucial for the proper development of EBs (fig. 1C). If EBs are transferred too early, as already described in detail in Bader et al. [2001], no critical mass of cells can develop and thus no primitive endoderm forms (fig. 1C, a). Most of these too-small EBs die and 
Fig. 2. Attachment of EBs to a surface leads to the development of a bilateral symmetrical cell aggregate. A-E Attachment of EBs to gelatine-coated tissue culture plates between days 4.5 and 6. C Arrow shows first attaching primitive endodermal cells. D, E Brackets show proliferating primitive endoderm. F, G Development of EBs between days 5 and 6. F Arrow shows migrating primitive endodermal cells. G, H Brackets show parietal endodermal cells undergoing an epithelial-mesenchymal transition. $\mathbf{H}$ In the meantime, the core of the EBs starts to elongate. I Cartoon: cross section of a typical EB at days 5 and 6 . Inner cells of primitive ectoderm (pink) are surrounded by primitive endoderm (blue) which differentiates upon contact with the gelatine-coated tissue culture plate (green) into parietal endoderm (yellow) and visceral endoderm on top of the primitive ectoderm, respectively. J-L Breaking of the point symmetry by elongation of the central dense core of the EBs between day 6.5 and 7.5. Dashed lines indicate the forming axis. Solid lines emanating from the center (dots) of EBs indicate the asymmetric elongation of the EB core. $\mathbf{K}$, $\mathbf{L}$ Arrows indicate areas where the thin cell layer (mesoderm?) forms which later separates the horseshoe-shaped area from the center of the EBs. $\mathbf{M}-\mathbf{Q}$ Development of the horseshoe-shaped ridge of cells surrounding the core of the EBs between days 7 and 8.5. R, S Epithelial sheet of cells developing at the open side of the horseshoe-shaped ridge at day 6.5. Dashed line demarcates epithelial sheet of cells; dot shows center of EB. Inset $\beta$-Catenin staining of epithelial cells (green); bar: $10 \mu \mathrm{m}$. T, U Hematopoietic cells develop inside of the horseshoe-shaped area of EBs. Inset Single erythrocyte-like cells; bar: $10 \mu \mathrm{m}$; benzidine stain. $\mathbf{V}$ Cartoon of EB at day $8 \pm$ 1: transverse section through the center of the EB. W Pseudo-3-D image (tilted illumination under a stereomicroscope) of a day-8 EB where pseudocoloring indicates the area of developing presumptive mesoderm (brown), the epithelial sheet of cells at one end of the EB (yellow), and the dense horseshoeshaped area of presumptive ectoderm (black) which is surrounded by the extraembryonic endoderm (green-blue). The central black area may be a remnant of the primitive endoderm covered by visceral endoderm. X, Y Blurring of the horseshoe-shaped ridge by cell growth and migration starting at day 8.5-9.0. Dashed lines indicate 2-fold axes. A-E, J-L, $\mathbf{O}, \mathbf{U}, \mathbf{V}$ Bright-field illumination. F-H, M, N, R, S Phase-contrast illumination. P, Q, X, Y Dark-field illumination. Bars: $100 \mu \mathrm{m}$ except for $\mathbf{S}: 50 \mu \mathrm{m}$.
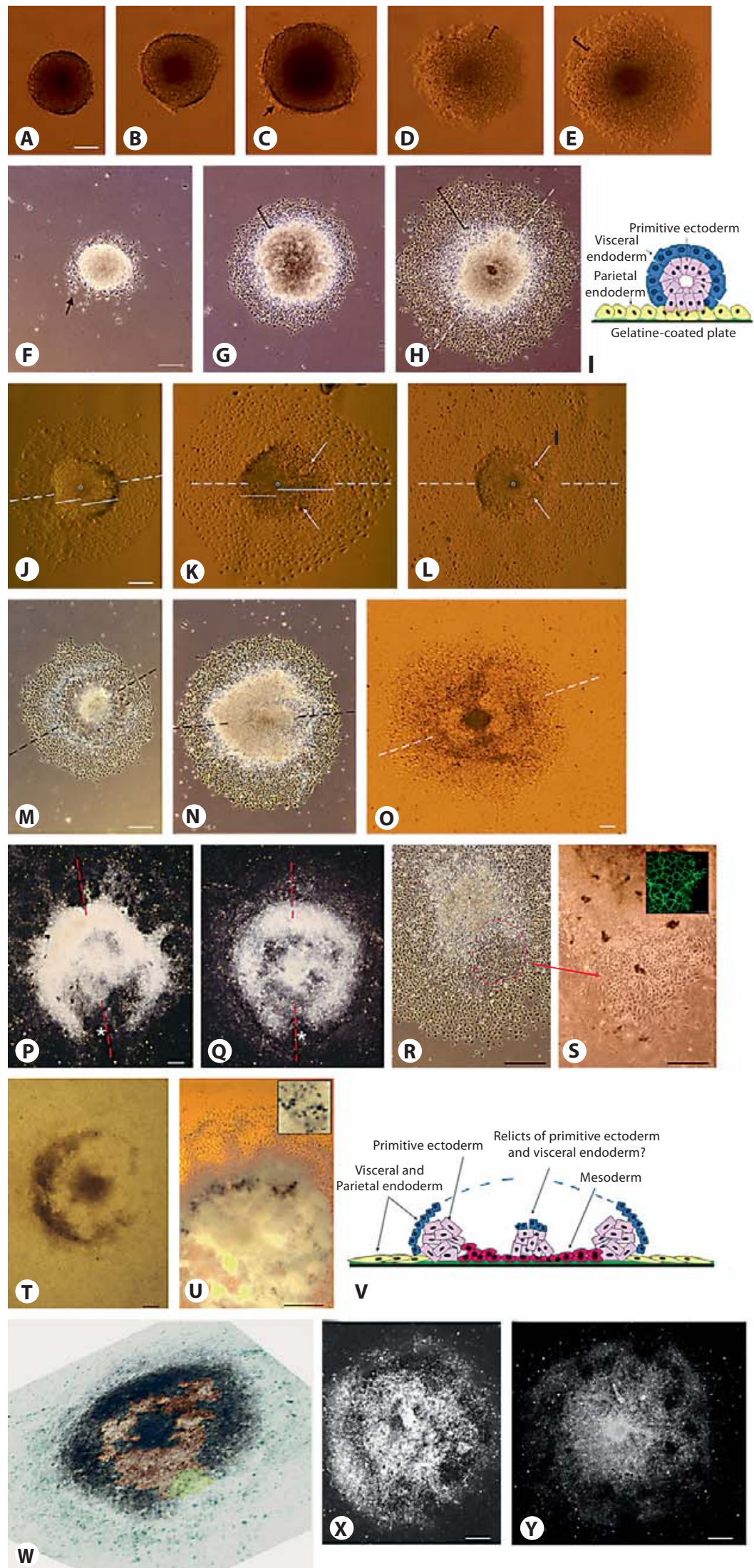

Fuchs/Scheinast/Pasteiner/Lagger/ Hofner/Hoellrigl/Schultheis/Weitzer 
Fig. 3. Development of the primitive endoderm after the attachment of EBs. Toluidine blue $\mathrm{O}$ staining of endodermal cells: epithelial primitive and visceral endoderm (dark purple), mesenchymal parietal endoderm (bright rose and arrows) [Bader et al., 2001]. Attached EB at day 5 (A), day 6 (B), day $7.5(\mathbf{C})$, day 8.5 (D, E), day $12(\mathbf{F})$. Bright-field image. Bars: $100 \mu \mathrm{m}$.
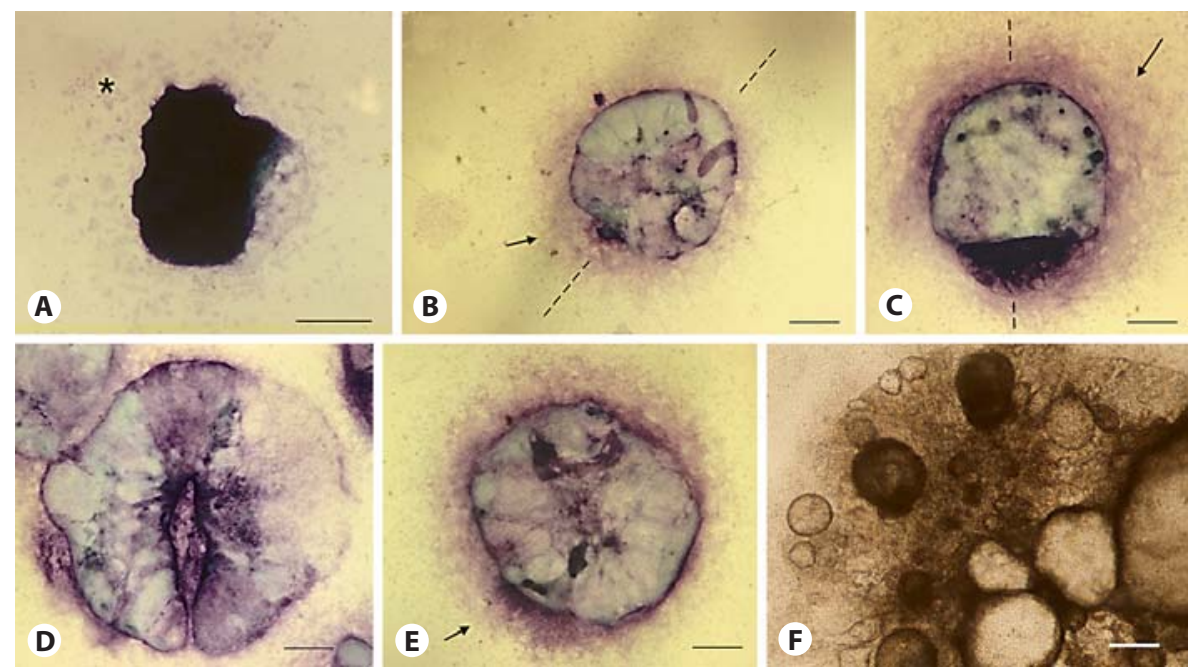

those which survive and attach to plates remain as small colonies with an ESC-like morphology (fig. 1C, b). When plated at day 4.5, almost all EBs have a uniform, radial symmetrical morphology (fig. 1C, c) with a flat outer layer of parietal endoderm. If plated after day 4.5, a large number of EBs develop an irregular shape (fig. 1C, d), but 1-2 days later proceed in their development similarly to those plated on day 4.5 (fig. 1C, e). If plated after day 6.5, the majority of EBs become encapsulated and blocked by their own overgrowing primitive endoderm (fig. 1C, f), which may give rise to parietal endoderm (brackets in fig. $1 \mathrm{C}, \mathrm{g}, \mathrm{h}$ ), but at the same time physically prevents the inner cells escaping from the endodermal shell by forming a thick Reichert's membrane-like structure (arrows in fig. 1C, g, h).

In contrast, when transferred from hanging drops to gelatine-coated tissue culture plates at day 4.5, axis formation becomes evident in EBs by the development of morphological distinct cell populations (fig. 2). Spherical EBs attach via their outermost cell layer of primitive endoderm to the culture plates (fig. 2A-C). Primitive endoderm starts to proliferate radially around the dense core of the EBs composed of undifferentiated cells (fig. 2D, E) between days 4.5 and 5.5. Then primitive endoderm cells migrate distally (fig. 2F) and simultaneously develop into parietal endoderm (fig. 2G). Radial symmetry is maintained during this short period of time. On top of the core of EBs, the remaining primitive endoderm develops into visceral endoderm [Bader et al., 2001; Stary et al., 2005] (fig. 2I). Between days 6 and 7.5 an axis forms which becomes evident, firstly, by an elliptical shape of the dense center of the EBs (fig. $2 \mathrm{H}, \mathrm{J}, 6 \mathrm{~B}$ ), secondly, by the forma- tion of a cavity on the elongated side of the dense center filled with a thinner layer of cells (fig. $2 \mathrm{~K}, \mathrm{~L}$ ), and finally, by the formation of a dense horseshoe-shaped ridge which migrates distally away from the also-dense core of the attached EBs (fig. 2M-Q, 6B). At the same time, radial symmetry is also broken by the appearance of an epithelial, $\beta$-catenin-positive sheet of cells which reside at the opening of the horseshoe-shaped ridge. This allows definition of, in addition to the 2-fold axis, an 'anterior' and a 'posterior' half of the EBs (fig. 2R, S). At the inner side of the horseshoe-shaped ridge hematopoietic cells develop (fig. 2T, U), which suggests that primitive mesoderm evolves in this part of the EBs, as depicted in the cartoon (fig. 2V) and the false-colored picture of an EB (fig. 2W). This finding is in line with a previous observation of Brachyury-expressing cells in this part of EBs [Bader et al., 2001].

This morphological development only takes place when EBs are not disturbed by secreted factors coming from other EBs in the close vicinity, and when the initial number of aggregated ESCs ranges between 500 and 800 cells. The latter also correlates well with the observation that cardiomyogenesis was optimal when these ESC numbers were used to generate EBs [Bader et al., 2001]. Development of these morphological features was observed in 3 independently generated and genetically distinct ESC lines, AB2.2, W4 and 663. After day 8, the axis became blurred by cell proliferation and/or migration within the center and horseshoe-shaped ridge of the EBs (fig. 2X, Y), or by excessive proliferation of visceral endoderm which formed large epithelial bubbles on top of the EBs (fig. 3F). 

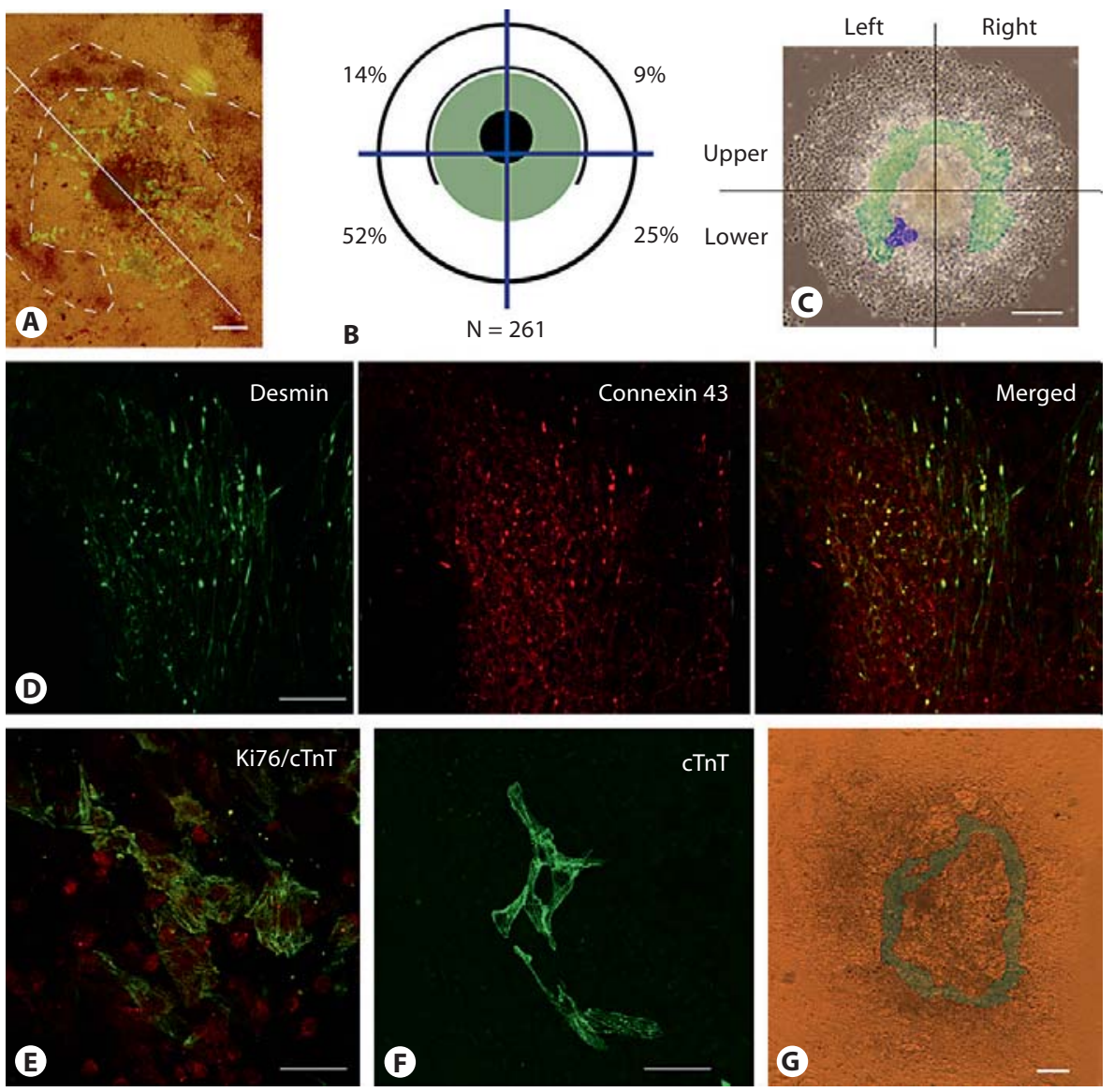

Fig. 4. Development of first rhythmically contracting CMCs breaks the bilateral symmetry in EBs. A Localization of CMCs between the horseshoe-shaped ridge of cells and the core of the EBs at day 9. Immunofluorescence staining of CMCs with MHCalpha antibodies. Fluorescence image was overlaid onto the bright-field image. Dashed line demarcates the horseshoe-shaped ridge; the axis is indicated by a white line. B Schematic drawing of the EB composed of a dense center surrounded by a horseshoeshaped dense ridge of cells. Distribution of the first rhythmically contracting CMCs in EBs is shown in the area highlighted in green, the black circle indicates the rim of the EB, blue lines demarcate the quadrants where the first contracting CMCs were located. Percentages of EBs wherein a single cluster of CMCs first started to contract are indicated. Total number of EBs monitored in 3 experiments was 373. C Area where first CMCs were located

During the same time interval as primitive ectoderm gives rise to mesoderm and the horseshoe-shaped ridge defines a bilateral axis and an anterior and posterior end of EBs, the epithelial primitive endoderm on top of the center of EBs (fig. 3A, dark purple) develops into both epithelial visceral endoderm (dark purple) doming above the invisible ectodermal core, and parietal endoderm in EBs. False colors on top of a phase-contrast image of a typical EB at day 7.8: green shows the 'gap-like' area between the dense center of the EBs and the horseshoe-shaped ridge of cells, purple indicates the place where the majority of the first CMCs become visible. D Double-immunofluorescence staining of developing CMCs with Desmin (green) and Connexin 43 (red) antibodies. Note Connexin 43-positive and Desmin-negative epithelial cells at the lower right area of the image. E Double-immunofluorescence staining of developing CMCs with Ki67 (red) and cardiac Troponin T (cTnT) antibodies (green). F Immunofluorescence staining of more mature CMCs with cTnT antibodies. G Ringlike network composed of rhythmically and synchronously contracting CMCs at day 12. Contracting cells are highlighted in green. Bright-field image. Bars: $100 \mu \mathrm{m}(\mathbf{A}, \mathbf{C}, \mathbf{G}), 20 \mu \mathrm{m}$ (D, E), $40 \mu \mathrm{m}(\mathbf{F})$.

(bright rose) circumjacent to the central part of EBs (fig. 3B). Between days 6 and 7 endodermal cells are always more dense at one side of the EBs than in other areas (fig. 3B, C), which may well reflect the formation of a bilateral axis in the underlying primitive ectoderm. These densely packed cells on one side of the EBs might well correlate with the epithelial cell sheet next to the opening of 

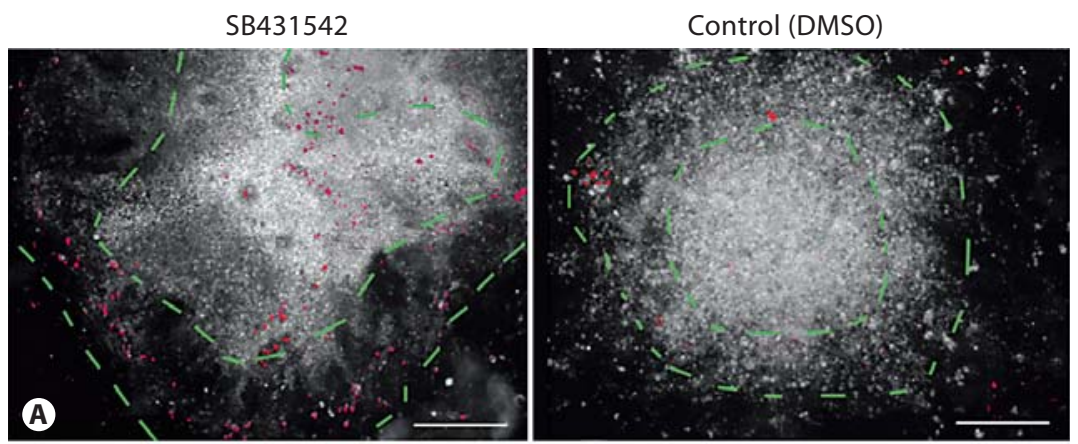

Fig. 5. Inhibition of Nodal-ALK4 signaling causes cell death in the area between the dense center and the horseshoe-shaped ridge in EBs. A Day-7 EB cultured in the presence of $3.8 \mu \mathrm{mol} / \mathrm{l} \mathrm{SB} 421542$ from day 3 to day 7. Dark-field image overlaid with red fluorescent image of propidium iodide-stained nuclei of dead cells. Dashed lines in A (green) and B (purple) demarcate area where mesoderm forms. B Day-11 EB cultured in the presence of $3.8 \mu \mathrm{mol} / \mathrm{l}$ SB421542 from day 3 to day 11 . Note dark ring of dead cells in the presence of SB431542. Phase-contrast images. C Fluorescence image of propidium iodide staining of dead cells in areas indicated by rectangles in B. D Onset of cardiomyogenesis in EBs treated with SB431542. E Cardiomyogenesis in EBs in the presence of 3.8 $\mu \mathrm{mol} / 1 \mathrm{SB} 431542$ in wild-type and des $^{\text {ect }}$ EBs, respectively. Note increased percentage of EBs surviving SB431542 treatment in the presence of ectopically expressed Desmin. Same volume of DMSO was added to all controls as used to administer SB431542. F Cardiomyogenesis in $\mathrm{des}^{-/-}$ and in des $^{\text {ect }}$ EBs in the presence of 58 $\mathrm{nmol} / \mathrm{l}$ recombinant Nodal. Data are from 2 experiments (error bars, standard deviation). $\mathrm{p}<0.05$. Number of EBs checked per experiment: 180. Bars: $200 \mu \mathrm{m}$ (A), 100 $\mu \mathrm{m}$ (B), $50 \mu \mathrm{m}$ (C).
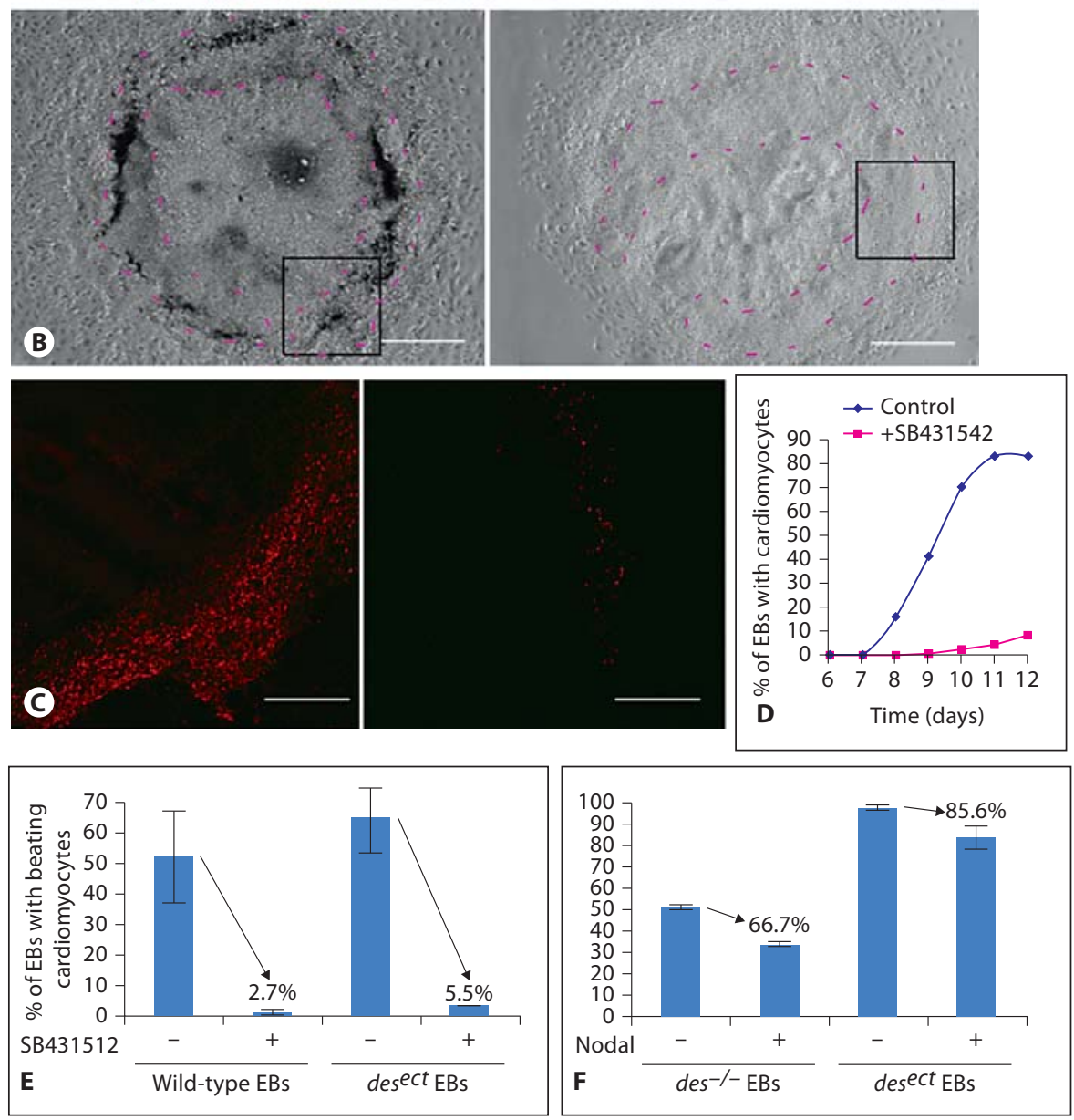

the horseshoe-shaped ridge (fig. 2R). Very rarely visible, the endoderm remains attached to the core of the EBs, as suggested in the cartoon in figure $2 \mathrm{~V}$, and the underlying horseshoe-shaped morphology becomes visible (fig. 3D). After day 8 of the EB development, again the axis becomes blurred by chaotic growth of all three germ layers (fig. 3E) and finally endoderm develops into large, randomly located bubbles composed of epithelial cells which cover and obscure the inner parts of all EBs (fig. 3F).

\section{Cardiomyogenesis Temporally Breaks the Bilateral}

Symmetry in EBs

In mammals, the heart is the first organ which forms during embryogenesis. Similarly, CMCs are the first somatic cells whose function becomes apparent in EBs. Rhythmically contracting CMCs emerge exclusively in the mesodermal part between the dense core and the dense horseshoe-shaped ridge of EBs (fig. 4A). To determine whether CMCs form in random distribution 
Fig. 6. Ectopic expression of the early muscle-specific protein Desmin disturbs morphogenesis in EBs. A Semiquantitative RTPCR analysis of mRNAs isolated from developing EBs at times indicated. GAPDH was loading control. Alpha fetoprotein (AFP) was used as control to monitor differentiation of endoderm. B Typical morphology of wild-type $\left(\right.$ des $\left.^{+/+}\right)$and $\mathrm{des}^{+/+}$ des $^{e c t}$ EBs at days 6-7. C des $^{+/+} d e s^{e c t}$ EBs at days 8-9. D Development of asymmetric centers in $\operatorname{EBs}(\boldsymbol{\Delta})$, horseshoe-shaped ridges surrounding the centers (O), and rhythmically contracting CMCs ( $\boldsymbol{\square})$ in wild-type (red lines; $\mathrm{n}=788$ ) and $\mathrm{des}^{+/+}$ des $^{\text {ect }}$ (blue lines; $\mathrm{n}=706$ ) EBs. Standard deviation was always less than $15 \%$ and is omitted for clarity reasons. E An aggregate of somatic stem cells isolated from murine hearts at day 13 after aggregation. B Phasecontrast images. C, E Dark-field pictures composed of several images. Areas with rhythmically contracting CMCs are highlighted in green. Bars: $200 \mu \mathrm{m}$ (B), $100 \mu \mathrm{m}$ (C), $1 \mathrm{~mm}(\mathbf{E})$.

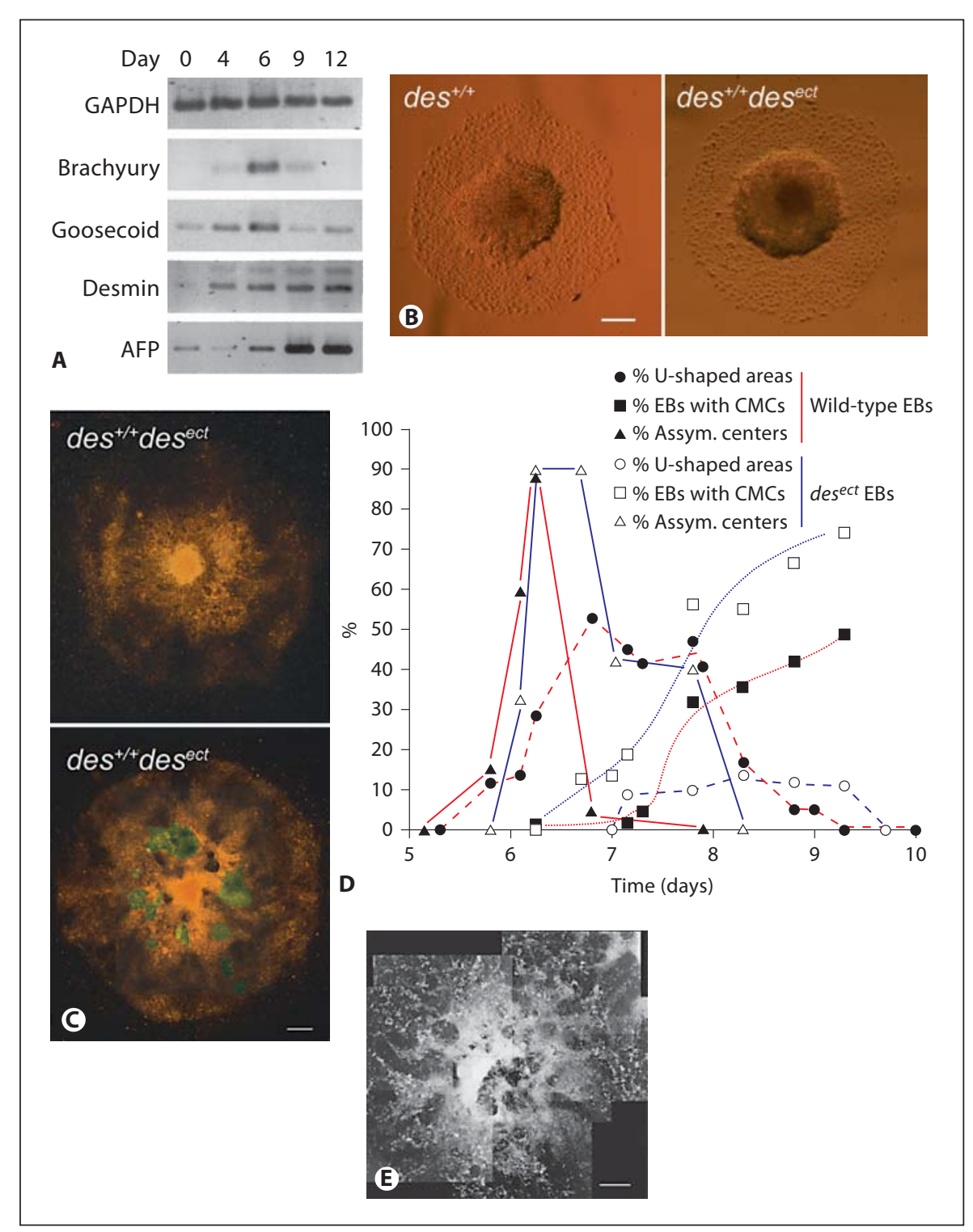

throughout the mesodermal area or in some ordered fashion in relation to the 2-fold axis of the EBs, we determined the location of the first beating cluster of CMCs in EBs between day 6.7 and day 7.5 (fig. 4B). The percentage of EBs with beating CMCs when the maximum was reached on day 11 after aggregation was $89 \pm 11 \%$ (table 1). CMCs started to beat in $83 \pm 8 \%$ of these EBs ( $\mathrm{n}=$ 373 ) in the lower half, where the horseshoe-shaped ridge opened and the epithelial, $\beta$-catenin-positive sheet of cells formed. From these EBs, $69 \pm 13 \%$ had a single asymmetrically located cluster of beating cells on one side of the 2-fold axis near the epithelial cell sheet, and $32 \pm$ $13 \%$ had 2 symmetrically located clusters of beating
CMCs on both sides of the 2-fold axis. Of those with only a single cluster on one side of the axis, $52 \pm 18 \%$ started to contract in the lower left area (observed from the 'dorsal' side of the EBs facing the medium), and $25 \pm 8 \%$ in the lower right area $(n=261)$. In the upper area of the EBs, $14 \pm 4 \%$ started to contract on the left side and $9 \pm 6 \%$ on the right side. The color scheme on top of the representative EB (fig. 4C) depicts the location where the majority of first CMCs emerged (purple area) and the area where CMCs may have emerged later on during development (green area). To identify early CMCs in the lower left quadrant of EBs, we used Desmin antibodies because Desmin is one of the first muscle-specific proteins ex- 
pressed in CMCs long before regular myofibrils form [Kuisk et al., 1996], in conjunction with Connexin 43 antibodies which detect both gap junctions in epithelial cells and costameres in CMCs (fig. 4D). These CMCs still have the capacity to proliferate (fig. 3E) and develop into myofibrils containing CMCs (fig. 4F).

These data together suggest that the morphology of EBs influences the local appearance of the first rhythmically contracting clusters of CMCs. The clear bias towards the 'lower left quadrant' of the EBs (fig. 4B, C) breaks the axial symmetry of the EBs and may allude to the asymmetric location of organs in bilateria later in development. At day $8.2 \pm 0.5$, many EBs have large and interconnected clusters of rhythmically contracting CMCs which surround the center of EBs in a ring-like structure which always remains localized clearly within the horseshoe-shaped ridge (fig. 4G).

Mesoderm Formation and Cardiomyogenesis Requires ALK-4-Mediated Signaling in EBs

Nodal is a key regulator of mesoderm development which targets mesoderm-regulating genes such as Lefty $\mathrm{A} / \mathrm{B}$ and Brachyury via the ALK4 receptor kinase and Smad proteins [Dvash et al., 2007]. To test whether mesoderm formation indeed takes place in the area between the dense core and the horseshoe-shaped ridge, and whether the horseshoe-shaped ridge in EBs depends on Nodal signaling, we added the ALK4 inhibitor SB431542 to the medium starting from day 3 of EB development, right before Brachyury expression became evident in the EBs (fig. 6A). In the presence of the $3.8 \mu \mathrm{mol} / \mathrm{l} \mathrm{SB} 431542$ the number of dying cells was apparently increased in a ring-like area around the center of the EBs at day 7 (fig. 5A). In the absence of SB431542 but in the presence of DMSO, only very few cells, scattered all over the EBs, were dying. Formation of a horseshoe-shaped ridge was never observed. At day 11, dead cells accumulated in a ring-like area around the center of the EBs (fig. 5B), in which most cells had become permeable for propidium iodide (fig. 5C). Increased death of cells in the mesodermal compartment of EBs resulted in a significant delay of cardiomyogenesis by 2 days (fig. 5D) and decreased cardiomyogenesis (fig. 5E) in the presence of SB431542. Most importantly, the negative effect of SB431542 on cardiomyogenic mesoderm was significantly attenuated when desmin [Hofner et al., 2007], known to promote the differentiation and survival of myocardial mesoderm, was overexpressed in EBs. Notably, the addition of 58 $\mathrm{nmol} / \mathrm{l}$ Nodal from day 3 onwards did partially inhibit cardiomyogenesis, most likely because Nodal itself also prevents differentiation of ESCs [Vallier et al., 2004, 2009]. Again, Desmin expression attenuated the negative effect of Nodal in EBs, which suggests that SB431542 indeed specifically blocks ALK4 and affects the development of mesoderm. These data together support the morphological observations, are in line with previous reports [Behr et al., 2005; Denker et al., 2007; Maranca-Huwel and Denker, 2010] and suggest that mesoderm indeed forms in EBs by the ingression of cells around the center of EBs between days 6 and 7 .

\section{Ectopic Expression of Desmin in EBs Randomizes}

the Localization of the First CMCs and Disturbs the

Morphology of EBs

We previously demonstrated that ectopic and constitutive expression of Desmin protein promotes cardiomyogenesis in EBs by the upregulation of mesodermal transcription factor Brachyury and Nkx 2.5 [Hofner et al., 2007] and that a desmin null mutation and the ectopic expression of dominant negative mutant desmin alleles hamper cardiomyogenesis [Höllrigl et al., 2007]. RT-PCR analysis of the expression of mesodermal transcription factors Brachyury and Goosecoid in developing EBs demonstrates that desmin mRNA is expressed in advance of Brachyury mRNA (fig. 6A). From these data we reasoned that the ectopic expression of Desmin protein may increase the commitment of primitive mesoderm towards the cardiomyogenic lineage, and consequently influence the development of the mesoderm at very early stages and the appearance of the outlying horseshoeshaped ridge in EBs. Until day 5-6, when the asymmetry of the centers of EBs became visible, EBs with an ectopically expressed desmin allele (des ${ }^{\text {ect }}$ ) developed into indistinguishable wild-type EBs (fig. 6B). At the time when the horseshoe-shaped ridge became apparent in wildtype EBs, the majority of $\mathrm{des}^{+/+} \mathrm{des}^{e c t} \mathrm{EBs}$ had a uniform central mass of cells with a random distribution of contracting CMCs (fig. 6C) and no bilateral axis became visible.

The development of the asymmetric dense core of EBs between days 5 and 6.5 was indistinguishable between wild-type and $d e s^{+/+} d e s^{e c t}$ EBs (fig. 6D, solid lines) but the frequency of horseshoe-shaped ridges was significantly reduced in $\mathrm{des}^{+/+} \mathrm{des}^{e c t} \mathrm{EBs}$ and the evolution of this structure was also delayed (fig. 6D, dashed lines). Notably, the epithelial sheet of cells at one end of the wild-type EBs was never observed in $\mathrm{des}^{+/+} \mathrm{des}^{\mathrm{ect}} \mathrm{EBs}$ and the first CMCs were always evenly distributed throughout the mesodermal area. However, cardiomyogenesis commenced earlier than in wild-type EBs and the number of EBs with CMC 
clusters was significantly increased (fig. 6D, dotted lines). This effect was Desmin specific and not caused by the genetic manipulation of ESCs because homozygous knockout of the histone deacetylase 1, the leukemia inhibitory factor and the leukemia inhibitory factor receptor loci did not interfere with the morphological development observed in wild-type EBs, but did influence cardiomyogenesis later on [data not shown; Bader et al., 2001; Lagger et al., 2002; Lauss et al., 2005; Lagger et al., 2010]. Therefore, disturbing the development of mesoderm by overexpression of Desmin, pushing the cells to become CMCs, or selectively killing some mesodermal cells with SB431542 negatively affects morphogenesis in EBs.

To test whether self-organization and morphological development are a general phenomenon in aggregated stem cells or restricted to pluripotent ESCs, we aggregated cardiovascular progenitor cells in the same way as ESCs. Cardiovascular progenitor cells were isolated from newborn mouse heart, (unpubl. results). After aggregation for 4.7 days, cardiovascular progenitor cell aggregates were transferred to gelatine-coated tissue culture plates, where they attached and cells started to divide and migrate distally similar to ESC-derived EBs (fig. 6E). These cells give rise to CMCs, smooth muscle and endothelial cells [Srivastava and Ivey, 2006]. Notably, none of these aggregates ever developed a horseshoe-shaped ridge or an epithelial sheet of cells, which break the point symmetry in EBs. First CMCs developed in even distribution throughout the entire center of all aggregates similar to those EBs where Desmin was constitutively expressed in all cells. From these results we may infer that self-organization of germ lineages is restricted to ESC-derived EBs.

\section{Discussion}

ESCs were studied mainly to understand the molecular mechanisms involved in self-renewal and the differentiation to somatic cells. Aggregation of ESCs in EBs turned out to be a strong signal inducing the differentiation of ESCs, which leads to the development of numerous somatic cells descending from all three germ layers. Cell biological analysis of differentiated cells, as well as the expression of lineage-specific genes during the differentiation processes, suggests that EBs undergo a developmental process resembling gastrulation in triploblastic embryos. Beyond this molecular data, only a few authors have thus far contributed to answering the question whether these differentiation processes are based on, or correlate with, morphological phenomena in EBs such as the self-organization of specific cells or pattern formation. Apart from very early approaches to describe the self-organization of cells in embryocarcinoma aggregates by Stevens $[1959,1960]$ and Pierce and Dixon [1959a, b], only Denker and colleagues [Behr et al., 2005; Denker et al., 2007; Maranca-Hüwel and Denker, 2010] and Nusse and colleagues [ten Berge et al., 2008] have convincingly demonstrated that gastrulation and axis formation may occur in EBs.

Here we demonstrate that a timely implantation-like process is a prerequisite for the breaking of the radial symmetry of EBs. Once attached to a surface, EBs develop a bilateral symmetry and mesodermal cells develop between the dense center of the EBs and a distal horseshoe-shaped ridge. The development of an epithelial sheet of cells at one side of the EBs but symmetrical to the axis allows definition of an 'anterior' and a 'posterior' end of the EBs. In the mesodermal area, first CMCs develop mainly next to the epithelial sheet of cells at one end of the bilateral EBs. Development of twice as many CMCs on the 'left' side of the EBs suggests that cardiomyogenesis causes or reflects a (temporal) asymmetry in EBs, which breaks the bilateral symmetry.

In vitro, in EBs it has so far generally been accepted that differentiation of germ layers is chaotic, that no organized migration of cells takes place and that the oxygen and nutrition supply by vessels is rudimentary or missing, and thus inefficient in supporting the self-organization of cells in EBs. Since chaos may be described as the most complex conceivable system, our constant effort is to reduce this complexity and demonstrate the simplicity of certain developmental processes in EBs. Therefore, we and many others developed a protocol which allowed the reproducible generation of uniform EBs. Reduced complexity resulted in the visibility of self-organization of cells in EBs. Most important was that aggregation of EBs started from a defined number of viable ESCs in the absence of any residual feeder cell [Bader et al., 2000a, 2001]. Secondly, the time of transfer of EBs to an ECM-coated tissue culture plate turned out to be essential for the consecutive ordered development. Another important condition was that EBs should not be influenced by close neighbors. If this occurred, we did not obtain a horseshoe-shaped ridge but rather irregular, or at best circular, structures around the center of EBs. Finally, the transfer of EBs at day 4.5 may have mimicked the implantation process in the murine uterus and induced primitive endoderm to differentiate to visceral and parietal endoderm, respectively. Parietal and visceral endoderm are well-described sources of growth factors supporting the 
differentiation of various cells which emerge during gastrulation. Notably, in many EBs, endodermal cells are more densely located at one side of the $\mathrm{EB}$, which might coincide with or even reflect the development of the epithelial sheet and axis formation.

Mesoderm formation followed the development of parietal endoderm presumably in cavities where cells seemed to ingress in elongating EBs. This could be the beginning of gastrulation by an epithelial-mesenchymal transition as described by Denker and colleagues [Behr et al., 2005; Denker et al., 2007; Maranca-Hüwel and Denker, 2010]. This process also marks the beginning of the axis formation. The cavities expand around the dense center of EBs and constitute the horseshoe-shaped ridge of EBs. The mesodermal cells then proliferate, perhaps pushing the horseshoe-shaped ridge more distally. Development of hematopoietic cells and CMCs within this horseshoe-shaped ridge strongly supports the previous finding that mesoderm forms in a central pit-like area of EBs. Induction of neurogenesis by retinoic acid (unpubl. results) exclusively gave rise to neurons at the periphery of the horseshoe-shaped ridge from day 8 onwards, which suggests that the remaining ectoderm is pushed outwards by the developing mesoderm. In conclusion, involution, migration and specification of mesoderm during EB development seems to recapitulate at least some early aspects of gastrulation.

While investigating the exact timing of cardiomyogenesis [Hofner et al., 2007; Höllrigl et al., 2007] it became evident that the spontaneous and rhythmical contraction of CMCs was unevenly distributed in the mesodermal ring-like area encircled by the horseshoe-shaped ridge. The majority of the first contracting CMCs developed on the 'lower left' side of EBs. Thus, commencing cardiomyogenesis seems to break the bilateral symmetry of EBs. One possible explanation for this unexpected finding can be the development of a morphogen gradient by ciliar movement under the dome of visceral endoderm which forms in many EBs on top of the gastrulating primitive ectoderm. Visceral endoderm in particular may shield the core of EBs from the medium or other environmental influences and provide a space in which morphogenetic gradients may form. ESCs possess primary cilia [Kiprilov et al., 2008] which, if maintained during the development of primitive ectoderm and gastrulation [Takaoka et al., 2007], may well generate a morphogen gradient by synchronous and unidirectional rotation. A unidirectional flow and a morphogen gradient under the doming visceral endoderm could contribute to the breaking of the bilateral symmetry.

Self-Organization in EBs
EBs also express increasing amounts of Nodal between days 3 and 5 [unpubl. results; Vallier et al., 2004] which might be unevenly distributed in or above EBs in a similar fashion as the flow of extraembryonic fluids creates morphogen gradients in embryos [Nonaka et al., 1998]. We were not able to demonstrate that Nodal indeed had this effect on breaking symmetry because the addition of recombinant Nodal always caused an increase in parietal endoderm formation obscuring the morphology of EBs and partially inhibited cardiomyogenesis. However, inhibition of endogenous, mesoderm-inducing Nodal signaling, by blocking the kinase activity of ALK4 with SB431542, resulted in a selective death of mesodermal cells in the ring-like area surrounding the dense core of EBs. Alternatively, asymmetric development of the first CMCs may be caused by paracrine factors secreted by the epithelial sheet or some other unidentified neighboring cell types. Asymmetry is observed only during the development of the very first CMCs. Later on CMCs emerge in a radial symmetric pattern scattered all over the mesodermal area encircled by the horseshoe-shaped ridge.

Previously, we and others could demonstrate that the muscle-cell-specific intermediate filament protein Desmin influences cardiomyogenesis at very early stages [Hofner et al., 2007; Höllrigl et al., 2007] and here we provide evidence that Desmin is expressed earlier than the maximum expression of Brachyury and Goosecoid in EBs. From these results we reason that the ectopic expression of Desmin might interfere with the asymmetric development of the first CMCs in the ring-like mesoderm. The ectopic expression of Desmin did not interfere with axis formation in EBs, but indeed hampered the formation of the horseshoe-shaped ridge in most EBs. Concomitantly, first CMCs evenly dispersed throughout the mesodermal area started to contract and cardiomyogenesis was consequently strongly increased [Hofner et al., 2007]. Thus uniform and constitutive expression of Desmin in all cells prevents the temporal formation of an asymmetric pattern but not the development of the mesoderm itself.

The total absence of axis formation in aggregates made of cardiovascular progenitor cells and the uniform distribution of CMCs throughout the entire aggregate, without any bias in regard to their localization, suggest that gastrulation-like processes observed in EBs are based on the unique features of ESCs, which enables EBs to undergo cellular self-organization and development of somatic derivates of all three germ layers. Beyond gastrulation and formation of somatic cells, however, it must be stated 
that EB development clearly deviates from murine embryogenesis once organs start to form in the murine embryo between days 7 and 8 . In EBs we only saw the development of certain cell types but neither formation of complex tissues nor organs.

Once these conditions are translated to human ESCs, EBs may well become a valuable model system not only for the in vitro analysis of genetic defects and gene function, which has contributed to reducing the number of animal experiments in the past, but also for early morphogenetic processes recapitulating pregastrulation and early gastrulation of the human embryo in vitro; this could not otherwise be studied due to ethical reasons.

\section{Acknowledgements}

We thank Dr. Allan Bradley for the AB2.2 ESCs and SNL76/7 fibroblasts which we have used now for 17 years in our laboratory without any phenotypic changes. This work was supported by funds from the Austrian Fonds zur Förderung der wissenschaftlichen Forschung, grants P15303, P11189 and P18659; the Herzfelder'sche Familienstiftung; the Österreichische Nationalbank, grant 8437; the Austrian Federal Ministry of Science, grant GZ70.078/0002-Pr/472002; the Hochschuljubiläumsstiftung der Stadt Wien, grants H933-2003, H-2174/2007 and H-1249/2009 to G.W.

\section{References}

Aubert, J., S. Dessolin, N. Belmonte, M. Li, F.R. Dvash, T., D. Ben-Yosef, R. Eiges (2006) Human McKenzie, L. Staccini, P. Villageois, B. Barhanin, A. Vernallis, A.G. Smith, G. Ailhaud, C. Dani (1999) Leukemia inhibitory factor and its receptor promote adipocyte differentiation via the mitogen-activated protein kinase cascade. J Biol Chem 274: 24965-24972.

Bader, A., H. Al-Dubai, G. Weitzer (2000a) Leukemia inhibitory factor modulates cardiogenesis in embryoid bodies in opposite fashions. Circ Res 86: 787-794.

Bader, A., A. Gruss, A. Höllrigl, H. Al-Dubai, Y. Capetanaki, G. Weitzer (2001) Paracrine promotion of cardiomyogenesis in embryoid bodies by LIF modulated endoderm. Differentiation 68: 31-43.

Bader, M., H. Bohnemeier, F.S. Zollmann, O.E. Lockley-Jones, D. Ganten (2000b) Transgenic animals in cardiovascular disease research. Exp Physiol 85: 713-731.

Behr, R., C. Heneweer, C. Viebahn, H.W. Denker, M. Thie (2005) Epithelial-mesenchymal transition in colonies of rhesus monkey embryonic stem cells: a model for processes involved in gastrulation. Stem Cells 23: 805816.

Dani, C., I. Chambers, S. Johnstone, M. Robertson, B. Ebrahimi, M. Saito, T. Taga, M. Li, T. Burdon, J. Nichols, A. Smith (1998) Paracrine induction of stem cell renewal by LIFdeficient cells: a new ES cell regulatory pathway. Dev Biol 203: 149-162.

Denker, H.W., R. Behr, C. Heneweer, C. Viebahn, M. Thie (2007) Epithelial-mesenchymal transition in rhesus monkey embryonic stem cell colonies: a model for processes involved in gastrulation? Cells Tissues Organs 185: 48-50.

-Desbaillets, I., U. Ziegler, P. Groscurth, M. Gassmann (2000) Embryoid bodies: an in vitro model of mouse embryogenesis. Exp Physiol 85: 645-651. embryonic stem cells as a powerful tool for studying human embryogenesis. Pediatr Res 60: 111-117.

Dvash, T., N. Sharon, O. Yanuka, N. Benvenisty (2007) Molecular analysis of LEFTY-expressing cells in early human embryoid bodies. Stem Cells 25: 465-472.

Henry, M.D., K.P. Campbell (1998) A role for dystroglycan in basement membrane assembly. Cell 95: 859-870.

-Hofner, M., A. Höllrigl, S. Puz, M. Stary, G. Weitzer (2007) Desmin stimulates differentiation of cardiomyocytes and upregulation of Brachyury and Nkx2.5. Differentiation 75: 605-615.

Höllrigl, A., M. Hofner, M. Stary, G. Weitzer (2007) Differentiation of cardiomyocytes requires functional serine residues within the amino-terminal domain of desmin. Differentiation 75: 616-626.

Ikeda, W., H. Nakanishi, J. Miyoshi, K. Mandai, H. Ishizaki, M. Tanaka, A. Togawa, K. Takahashi, H. Nishioka, H. Yoshida, A. Mizoguchi, S. Nishikawa, Y. Takai (1999) Afadin: a key molecule essential for structural organization of cell-cell junctions of polarized epithelia during embryogenesis. J Cell Biol 146: 1117-1131.

Kiprilov, E.N., A. Awan, R. Desprat, M. Velho, C.A. Clement, A.G. Byskov, C.Y. Andersen, P. Satir, E.E. Bouhassira, S.T. Christensen, R.E. Hirsch (2008) Human embryonic stem cells in culture possess primary cilia with hedgehog signaling machinery. J Cell Biol 180: 897-904.

Komura, H., H. Ogita, W. Ikeda, A. Mizoguchi, J. Miyoshi, Y. Takai (2008) Establishment of cell polarity by afadin during the formation of embryoid bodies. Genes Cells 13: 79-90.
Kopper, O., O. Giladi, T. Golan-Lev, N. Benvenisty (2010) Characterization of gastrulation-stage progenitor cells and their inhibitory crosstalk in human embryoid bodies. Stem Cells 28: 75-83.

Kuisk, I.R., H. Li, D. Tran, Y. Capetanaki (1996) A single MEF2 site governs desmin transcription in both heart and skeletal muscle during mouse embryogenesis. Dev Biol 174: $1-13$.

Lagger, G., D. O'Carroll, M. Rembold, H. Khier, J. Tischler, G. Weitzer, B. Schuettengruber, C. Hauser, R. Brunmeir, T. Jenuwein, C. Seiser (2002) Essential function of histone deacetylase 1 in proliferation control and CDK inhibitor repression. EMBO J 21: 2672-2681.

Lagger, S., D. Meunier, M. Mikula, R. Brunmeir, M. Schlederer, M. Artaker, O. Pusch, G. Egger, A. Hagelkruys, W. Mikulits, G. Weitzer, E.W. Muellner, M. Susani, L. Kenner, C. Seiser (2010) Crucial function of histone deacetylase 1 for differentiation of teratomas in mice and humans. EMBO J 29: 3992-4007.

Laugwitz, K.L., A. Moretti, L. Caron, A. Nakano, K.R. Chien (2008) Islet1 cardiovascular progenitors: a single source for heart lineages? Development 135: 193-205.

Lauss, M., M. Stary, J. Tischler, G. Egger, S. Puz, A. Bader-Allmer, C. Seiser, G. Weitzer (2005) Single inner cell masses yield embryonic stem cell lines differing in lifr expression and their developmental potential. Biochem Biophys Res Commun 331: 1577-1586.

Li, Z., E. Colucci-Guyon, M. Pinçon-Raymond, M. Mericskay, S. Pournin, D. Paulin, C. Babinet (1996) Cardiovascular lesions and skeletal myopathy in mice lacking desmin. Dev Biol 175: 362-366.

Maranca-Hüwel, B., H.W. Denker (2010) Epithelial-mesenchymal transition in rhesus monkey embryonic stem cell colonies: the role of culturing conditions. In Vitro Cell Dev Biol Anim 46: 516-528. 
McMahon, A.P., A. Bradley (1990) The Wnt-1 (int-1) proto-oncogene is required for development of a large region of the mouse brain. Cell 62: 1073-1085.

> Milner, D.J., G. Weitzer, D. Tran, A. Bradley, Y. Capetanaki (1996) Disruption of muscle architecture and myocardial degeneration in mice lacking desmin. J Cell Biol 134: 12551270.

Murray, P., D. Edgar (2001) Regulation of the differentiation and behaviour of extra-embryonic endodermal cells by basement membranes. J Cell Sci 114: 931-939.

- Nakaya, K., M. Murakami, M. Funaba (2008) Regulatory expression of Brachyury and Goosecoid in P19 embryonal carcinoma cells. J Cell Biochem 105: 801-813.

Nonaka, S., Y. Tanaka, Y. Okada, S. Takeda, A. Harada, Y. Kanai, M. Kido, N. Hirokawa (1998) Randomization of left-right asymmetry due to loss of nodal cilia generating leftward flow of extraembryonic fluid in mice lacking KIF3B motor protein. Cell 95: 829837.

Pekkanen-Mattila, M., M. Pelto-Huikko, V. Kujala, R. Suuronen, H. Skottman, K. Aalto-Setala, E. Kerkela (2010) Spatial and temporal expression pattern of germ layer markers during human embryonic stem cell differentiation in embryoid bodies. Histochem Cell Biol 133: 595-606.

- Pierce, G.B., F.J. Dixon Jr (1959a) Testicular teratomas. I. Demonstration of teratogenesis by metamorphosis of multipotential cells. Cancer 12: 573-583.
Pierce, G.B., F.J. Dixon Jr (1959b) Testicular teratomas. II. Teratocarcinoma as an ascitic tumor. Cancer 12: 584-589.

Rula, M.E., K.Q. Cai, R. Moore, D.H. Yang, C.M. Staub, C.D. Capo-Chichi, S.A. Jablonski, P.H. Howe, E.R. Smith, X.X. Xu (2007) Cell autonomous sorting and surface positioning in the formation of primitive endoderm in embryoid bodies. Genesis 45: 327-338.

Soriano, P., C. Montgomery, R. Geske, A. Bradley (1991) Targeted disruption of the c-src proto-oncogene leads to osteopetrosis in mice. Cell 64: 693-702.

Srivastava, D., K.N. Ivey (2006) Potential of stem-cell-based therapies for heart disease. Nature 441: 1097-1099.

Stary, M., W. Pasteiner, A. Summer, A. Hrdina, A. Eger, G. Weitzer (2005) Parietal endoderm secreted SPARC promotes early cardiomyogenesis in vitro. Exp Cell Res 310: 331-341.

Stevens, L.C. (1959) Embryology of testicular teratomas in strain 129 mice. J Natl Cancer Inst 23: 1249-1295.

Stevens, L.C. (1960) Embryonic potency of embryoid bodies derived from a transplantable testicular teratoma of the mouse. Dev Biol 2: 285-297.

Swiers, G., Y.H. Chen, A.D. Johnson, M. Loose (2010) A conserved mechanism for vertebrate mesoderm specification in urodele amphibians and mammals. Dev Biol 343: 138 152.

Takaoka, K., M. Yamamoto, H. Hamada (2007) Origin of body axes in the mouse embryo. Curr Opin Genet Dev 17: 344-350. ten Berge, D., W. Koole, C. Fuerer, M. Fish, E. Eroglu, R. Nusse (2008) Wnt signaling mediates self-organization and axis formation in embryoid bodies. Cell Stem Cell 3: 508-518.

Vallier, L., S. Mendjan, S. Brown, Z. Chng, A. Teo, L.E. Smithers, M.W. Trotter, C.H. Cho, A. Martinez, P. Rugg-Gunn, G. Brons, R.A. Pedersen (2009) Activin/Nodal signalling maintains pluripotency by controlling Nanog expression. Development 136: 13391349.

Vallier, L., D. Reynolds, R.A. Pedersen (2004) Nodal inhibits differentiation of human embryonic stem cells along the neuroectodermal default pathway. Dev Biol 275: 403-421.

Weitzer, G. (2006) Embryonic stem cell-derived embryoid bodies: an in vitro model of eutherian pregastrulation development and early gastrulation. Handb Exp Pharmacol 174: 2151.

-Weitzer, G., D.J. Milner, J.U. Kim, A. Bradley, Y. Capetanaki (1995) Cytoskeletal control of myogenesis: a desmin null mutation blocks the myogenic pathway during embryonic stem cell differentiation. Dev Biol 172: $422-$ 439.

Wobus, A.M., H. Holzhausen, P. Jakel, J. Schoneich (1984) Characterization of a pluripotent stem cell line derived from a mouse embryo. Exp Cell Res 152: 212-219.

Yamanaka, S., J. Li, G. Kania, S. Elliott, R.P. Wersto, J. Van Eyk, A.M. Wobus, K.R. Boheler (2008) Pluripotency of embryonic stem cells. Cell Tissue Res 331: 5-22. 